\title{
Dental morphology of the Lesser Bamboo Rat, Cannomys badius (Rodentia, Spalacidae)
}

\author{
Raquel López-Antoñanzas' \\ I Departamento de Paleobiología, Museo nacional de Ciencias naturales-CSIC, C/ José Gutiérrez Abascal 2, \\ 28006 Madrid, Spain \\ Corresponding author: Raquel López-Antoñanzas (ralopan@mncn.csic.es)
}

Academic editor: K. M. Helgen | Received 13 August 2012 | Accepted 10 October 2012 | Published 17 October 2012

Citation: López-Antońanzas R (2012) Dental morphology of the Lesser Bamboo Rat, Cannomys badius (Rodentia, Spalacidae). ZooKeys 228: 69-75. doi: 10.3897/zookeys.228.3826

\begin{abstract}
Cannomys and Rhizomys are the sole living genera of the tribe Rhizomyini (Rhizomyinae, Spalacidae, Rodentia), known in the fossil record since the Late Miocene. The dental morphology of fossil Rhizomyini has been described in detail but until recently such descriptions were unavailable for extant species. A detailed account of the morphology and dental wear pattern of the cheek teeth of $C$. badius is provided here based on the examination of museum specimens. Three stages of wear are recognized. Cannomys shares with Rhizomys the synapomorphy of having a mesolophid that is a long continuation of the protoconid on the first lower molar. There are significant differences between these taxa, such as the much smaller size of the cheek teeth and the trilophodont dental pattern of the M2, M3, and m2 in Cannomys.
\end{abstract}

\section{Keywords}

Rhizomyinae, Rhizomyini, Cannomys, dental wear pattern

\section{Introduction}

The subfamily Rhizomyinae (Spalacidae, Rodentia) is known in the fossil record since the Oligocene. It is represented by three modern genera: the Asian bamboo rats $R h i$ zomys (a trispecific genus) and Cannomys (monospecific) and the African mole rats Tachyoryctes. The latter genus is considered bispecific by some authors (Missone 1971, Rahm 1980, Bucher 1982, Corbet and Hill 1991, Beolchini and Corti 2004), but this 
may be an underestimation of true diversity (Allen 1939, Ellerman 1941, Musser and Carleton 1993, 2005). The Asian bamboo rats belong to the tribe Rhizomyini, whereas Tachyoryctes is the only extant representative of the Tachyoryctini (Flynn 2009; LópezAntoñanzas et al. in press). The lesser bamboo rat Cannomys badius ranges from eastern Nepal, through northeast India, Bhutan, southeastern Bangladesh, Myanmar, south China, northwest Vietnam, Thailand and Cambodia (Musser and Carleton 2005). It is known to live in a wide variety of habitats, from bamboo forest to cultivated land and other modified areas (IUCN 2010).

Cannomys badius was originally named as Rhizomys badius by Hodgson (1841; p. 60 ) on the basis of a male specimen obtained "some miles north of the great valley" of Nepal. The type specimen is BMNH 1843.1.12.61 (skin and skull) (P. Jenkins, pers. comm. 2012). Thomas (1915a) created the new genus Cannomys for which he took Rhizomys badius as type, but in which he also included two other species: C. castaneus (Blyth 1843) and C. minor (Gray 1842). Thomas (1915b) later described another species of Cannomys, C. pater, and split C. castaneus into two subspecies (C. castaneus castaneus and C. castaneus plumbescens). Later, Gyldenstolpe (1916) described a new subspecies of Cannomys minor (C. minor lönnbergi). All these taxa are currently regarded as synonyms of $C$. badius (Musser and Carleton 2005).

The dental morphology of all living Rhizomyinae other than Cannomys badius, has been described in detail recently (Tachyoryctes; López-Antońanzas 2012) or are in the process thereof (Rhizomys). The aim of the present work is to provide an in-depth description of the dental morphology of Cannomys.

\section{Material and methods}

All the specimens of Cannomys badius housed in the Laboratoire de ZoologieMammifères et Oiseaux of the Muséum national d'Histoire naturelle, Paris, France $(\mathrm{MNHN})$ and in the Institut für Systematische Zoologie-Zoologische Sammlung of the Museum für Naturkunde, Berlin, Germany (ZMB) have been examined. MNHN individuals come from Thailand and Nepal, whereas those at ZMB are from Myanmar.

First, second, and third lower molars are designated as $\mathrm{m} 1, \mathrm{~m} 2$, and $\mathrm{m} 3$, respectively, and first, second, and third upper molars as M1, M2, and M3, respectively. The terminology used in the tooth descriptions follows the rodent dental terminology of Flynn (1982) with some adjustments (see Fig. 1).

\section{Dental morphology and wear pattern}

Incisors of Cannomys badius are strongly proodont, flattened anteriorly, lack major ornamentation and have the enamel pigmented orange.

The upper molars of Cannomys badius show unilateral hypsodonty, with crowns higher lingually than labially. M1 has four roots, the anterolabial one being the 


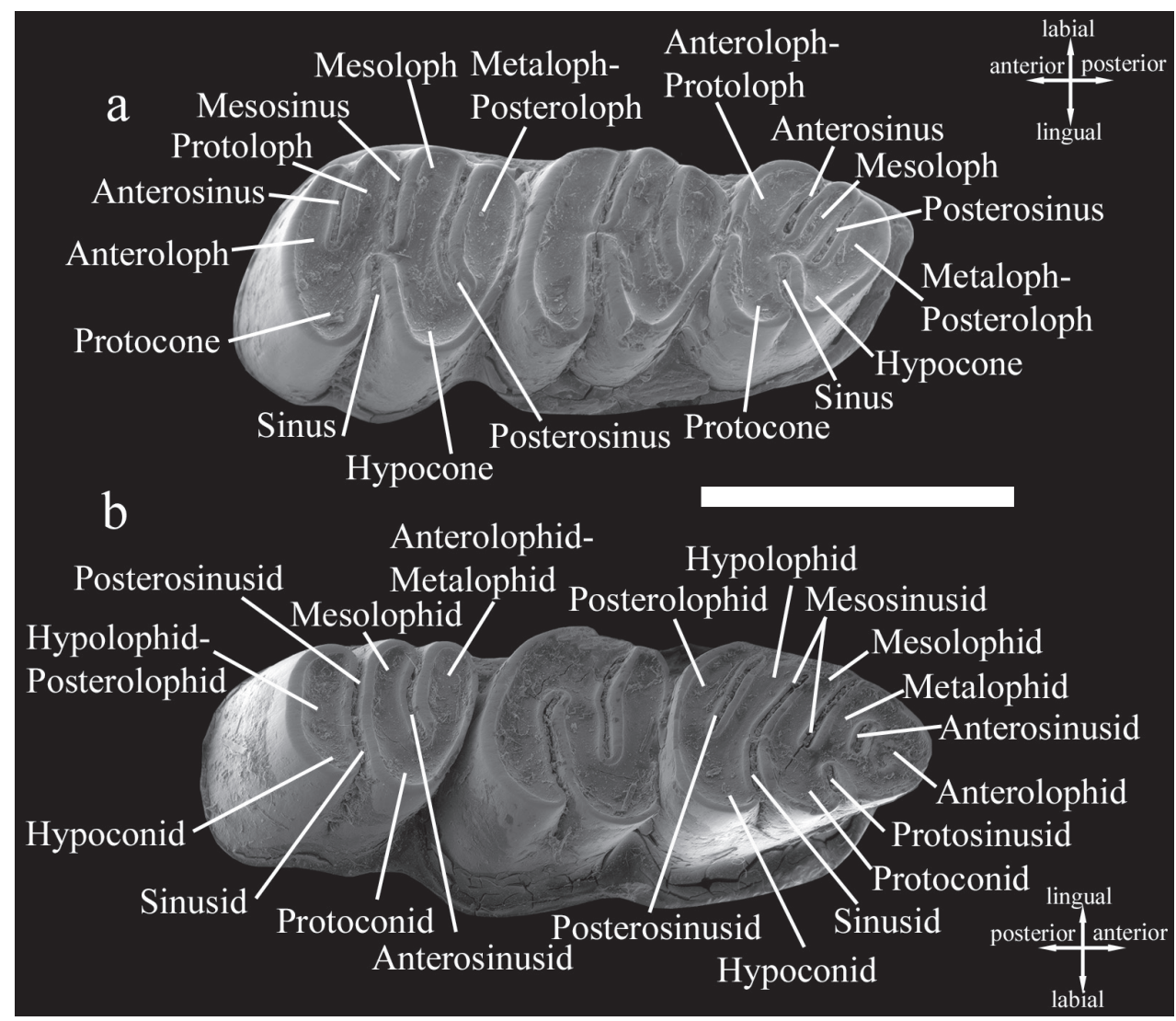

Figure I. Dental terminology used in this paper. Cannomys badius. a Left upper cheek teeth $\mathbf{b}$ Right lower cheek teeth. Scale bar equals $5 \mathrm{~mm}$.

most developed. Its occlusal outline is square. In early wear (e.g., MNHN C.G. 2000-271; Fig. 2a), it has four transverse lophs (anteroloph, protoloph, mesoloph, and metaloph-posteroloph) and all labial and lingual sinuses are open. In later wear (e.g., ZMB 44769 and MNHN C.G. 2000-761; Fig. 2b-c), the number of lophs is reduced to three as the anteroloph and protoloph combine and join at the margin of the tooth, isolating two transversely elongated enamel lakes, whereas the lingual sinus remains open. The latter, narrow and short, is directed toward the middle enamel lake. The connection between the anterior and posterior parts of the tooth persists through wear.

The occlusal outline of M2 is square, with its posterior side more reduced than the anterior one. This tooth is much shorter than M1. In early wear (e.g., MNHN C.G. 1860-382; Fig. 2a), it has three transverse lophs (anteroloph-protoloph, mesoloph, and metaloph-posteroloph). The sinus is directed toward the anterosinus. All reentrants remain open. After moderate wear (e.g., ZMB 44769, Fig. 2b), the sinus becomes narrower and the anterosinus and posterosinus are closed-off, isolating two enamel lakes. Late in wear (e.g., MNHN C.G. 2000-761; Fig. 2c), the morphology 


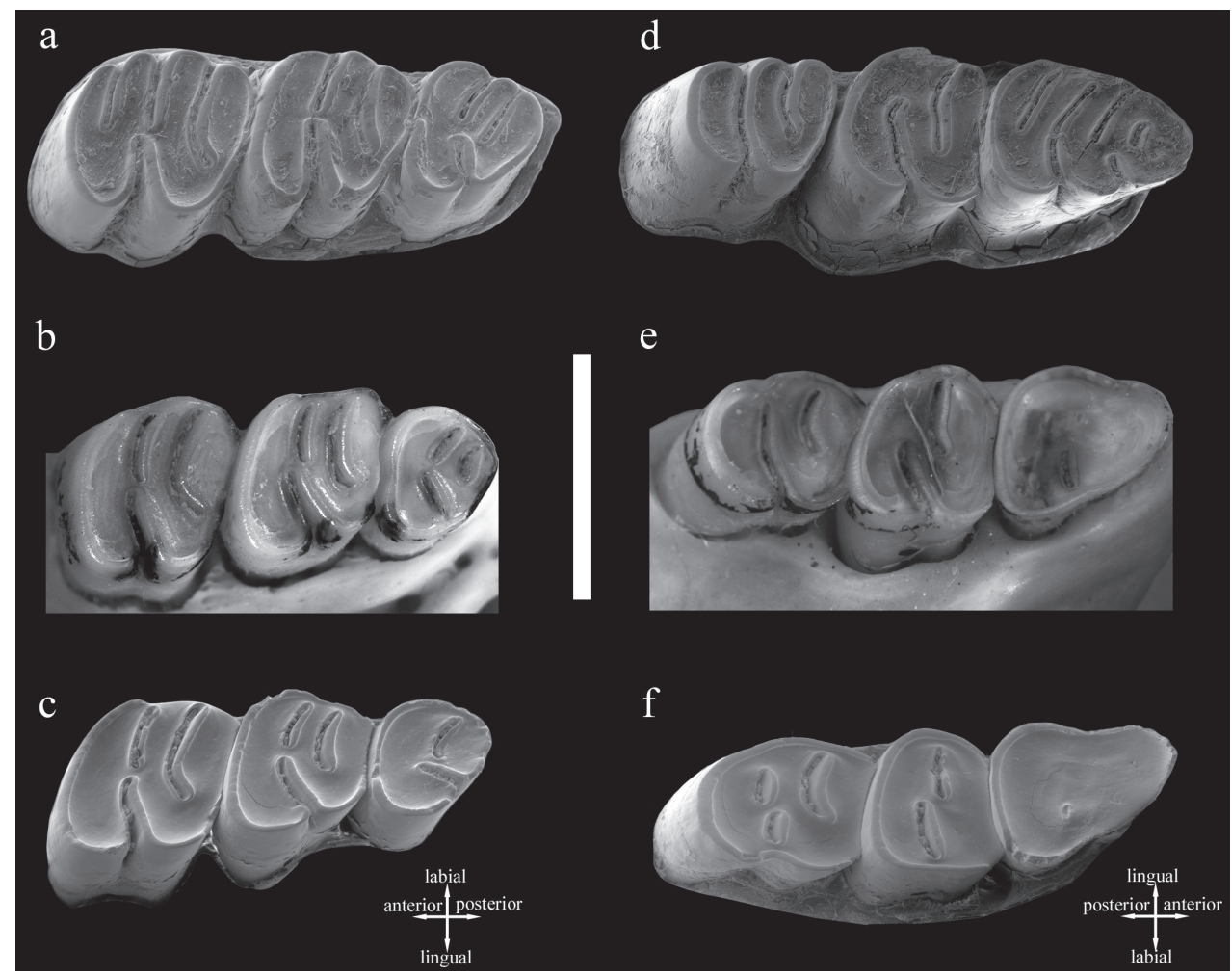

Figure 2. Dental wear pattern in Cannomys badius. a-c Upper molars: a Stage of wear 1, juvenile individual, left maxilla with M1-M3 in occlusal view (MNHN C.G. 1860-382) b Stage of wear 2, left maxilla with M1-M3 (ZMB 44769) c Stage of wear 3, left maxilla with M1-M3 in occlusal view (MNHN C.G. 2000-761). d-f Lower molars: $\mathbf{d}$ Stage of wear 1, juvenile individual, right hemimandible with $\mathrm{m} 1-\mathrm{m} 3 \mathrm{in}$ occlusal view (MNHN C.G. 1860-382), e Stage of wear 2, right hemimandible with m1-m3 in occlusal (ZMB 44768) f Stage of wear 3, left hemimandible with m1-m3 in occlusal (reversed) (MNHN C.G. 2000761). Scale bar equals $5 \mathrm{~mm}$.

of M2 is quite similar to that in the previous wear stage. However, the posterior part of the tooth becomes more reduced and, even though the lingual sinus remains open, it turns out to be more anterolabially directed due to the labial displacement of the hypocone. The connection between the anterior and posterior parts of the tooth persists through wear.

Cannomys has a reduced M3. In early wear (e.g., MNHN C.G. 1860-382; Fig. 2a), it is morphologically similar to M2 but with its posterior part smaller due to the more labial position of the hypocone. This tooth is trilophodont, with anterolophprotoloph, mesoloph, and metaloph-posteroloph. After moderate wear (e.g., ZMB 44769; Fig. 2b), the anteroloph-protoloph is nearly connected to the mesoloph and the metaloph-posteroloph joins the mesoloph, isolating a labial circular enamel lake. The hypocone is much more labially displaced and the sinus much more anterolabi- 
ally oriented. Therefore, the posterior part of the tooth becomes much reduced. In late wear (e.g., MNHN C.G. 2000-761; Fig. 2c), the first and second lophs combine and the anterior enamel lake disappears. At this stage of wear only a labial enamel lake persists and the hypocone is located on the posterior margin of the tooth.

The lower molars are lower crowned than the upper molars. As for the lower jaw bone, the mandibular foramen is located well caudal to the posterior margin of $\mathrm{m} 3$ (a little dorsal to $\mathrm{m} 3$, at the level of the tip of the coronoid process), whereas the mental foramen is situated rostrally to the anterior border of $\mathrm{m} 1$ (approximately on the midline of the dentary).

The occlusal outline of $\mathrm{m} 1$ is triangular, with its anterior part much narrower than its posterior. In early wear (e.g., MNHN C.G. 1860-382; Fig. 2d), it shows a pentalophodont dental pattern with anterolophid, metalophid, mesolophid, hypolophid, and posterolophid. The metalophid joins lingually the anterolophid and labially the protoconid, isolating a small and oval anterior enamel lake. The mesolophid is a long continuation of the protoconid. The anterior part of the tooth is isolated from the rest of the crown by a long sinusid. The latter results from the junction of the sinusid (or labial reentrant) with the mesosinusid (or middle labial reentrant). All lophids join the lingual margin of the tooth, isolating four transversely elongated enamel lakes. The $\mathrm{m} 1$ shows two open labial sinusids (protosinusid and sinusid). After moderate wear (e.g., ZMB 44768; Fig. 2e), all reentrants are closed-off, the protosinusid disappears, and the anterior part of the tooth is deprived of any enamel lake. However, two enamel lakes persist posteriorly. In late wear (e.g., MNHN C.G. 2000-761; Fig. 2f), the occlusal surface is completely flat and generally devoid of enamel lakes although a tiny and circular posterolabially located enamel lake may persist. The enamel has disappeared from the anterior border of the tooth, but it persists posteriorly.

The $\mathrm{m} 2$ has four roots, the posterior ones being the most developed. Its occlusal outline is square and it is anteroposteriorly compressed. In early wear (e.g., MNHN C.G. 1860-382, Fig. 2d); this tooth has three lophs (anterolophid-metalophid, mesolophid, and hypolophid-posterolophid). The mesolophid is short and joins labially the anterior lophid (through the protoconid) and lingually the posterior one. The sole lingual reentrant is closed-off, isolating a labial enamel lake, which is elongated. The narrow and posterolingually directed sinusid is open. After moderate wear (e.g., ZMB 44768, Fig. $2 \mathrm{e})$; the morphology of the tooth is similar to that of the preceding stage. In late wear (e.g., MNHN C.G. 2000-761; Fig. 2f), the sinusid is closed off and the tooth shows both a labial and a lingual enamel lake. The anterior side of the tooth loses the enamel.

In early wear (e.g., MNHN C.G. 1860-382; Fig. 2d), m3 has three lophids (anterolophid-metalophid, mesolophid, and hypolophid-posterolophid). The first lophid joins the second one through the protoconid. The posterior lophid is isolated from the rest of the crown by a long reentrant. At this stage of wear, all reentrants are open. After moderate wear (e.g., ZMB 44768, Fig. 2e), the lingual reentrants are closed-off. The tooth has an elongate anterior enamel lake and a long sinusid. In late wear (e.g., MNHN C.G. 2000-761; Fig. 2f), the lingual reentrant is closed-off, isolating two enamel lakes, and the anterior enamel lake persists. 


\section{Conclusion}

The examination of the cheek teeth in various specimens of Cannomys badius has allowed determining the changes undergone by the dental pattern during wear. Three fundamental stages of wear have been recognized.

As postulated by Flynn (1990), modern and extinct rhizomyines are united by dental features that include lophodonty, high crowned teeth, a strong wear gradient decreasing from first to last molar, junction between the metalophid and the anterolophid or the protoconid on the lower molars, and isolation of enamel lakes. In addition, Cannomys shares with Rhizomys, the other extant representative of the tribe Rhizomyini, the synapomorphy of having on the $\mathrm{m} 1$ a mesolophid that is a long continuation of the protoconid. However, Cannomys badius is much smaller than all the extant species of Rhizomys and exhibits the particularity of a trilophodont dental pattern on m2, M2, and M3, whereas it is tetralophodont in Rhizomys.

\section{Acknowledgements}

I sincerely thank C. Denys (Muséum national d'Histoire naturelle, Paris) and F. Mayer and N. Lange (Museum für Naturkunde, Berlin) for making available the rhizomyine material under their care. P. Jenkins (Natural History Museum, London) kindly answered all my inquiries. L. J. Flynn (Harvard University, Cambridge MA, USA), K. P. Aplin and K. M. Helgen (Smithsonian Institution, Washington DC, USA) helped to improve various aspects of this paper. M. Furió, A. García and L. Tormo (Museo nacional de Ciencias naturales-CSIC, Madrid) kindly took the SEMs.

My sojourns in Berlin and Paris were funded by the SYNTHESYS Project (http:// www.synthesys.info/), which is financed by the European Community Research Infrastructure Action under the FP7 "Capacities" Program, and by the EDIT Gender Action Plan, respectively. I am currently supported by the Ramón y Cajal Program and the research project CGL2011-24829.

\section{References}

Allen GM (1939) A checklist of African mammals. Bulletin of the Museum of Comparative Zoology at Harvard College 83: 1-763.

Beolchini F, Corti M (2004) The taxonomy of the genus Tachyoryctes: a geometric morphometric approach. Italian Journal of Zoology 71: 35-43. doi: 10.1080/11250000409356548

Blyth E (1843) Mr. Blyth's monthly Report for December Meeting, 1842, with Addenda subsequently appended. Journal of the Asiatic Society of Bengal 12: 925-1011.

Bucher JE (1982) Family Rhizomyidae. In: Honacki J, Kinmam KE, Koeppl JW (Eds) Mammals Species of the World, First Edition. Association of Systematics Collections, Lawrence, 477-478. 
Corbet GB, Hill JE (1991) A World List of Mammalian Species, Third edition. Oxford University Press, Oxford.

Ellerman JR (1941) The families and genera of living rodents. Volume II. Family Muridae. British Museum (Natural History), London.

Flynn LJ (1982) Systematic revision of Siwalik Rhizomyidae (Rodentia). Geobios 15: 327-389. doi: 10.1016/S0016-6995(82)80084-3

Flynn LJ (1990) The natural history of rhizomyid rodents. In: Nevo E, Reig OA (Eds) Evolution of subterranean Mammals at the organismal and molecular Levels. A.R. Liss, New York, 155-183.

Flynn LJ (2009) The antiquity of Rhizomys and independent acquisition of fossorial traits in subterranean muroids. Bulletin of the American Museum of Natural History 331: 128-156. doi: $10.1206 / 582-4.1$

Gyldenstolpe N (1916) Zoological Results of the Swedish Zoological Expeditions to Siam 1911-1912 \& 1914-1915. Mammals II. Kungliga Svenska Vetenskapsakademiens Handlingar 57: 1-59. doi: 10.5962/bhl.title.57007

Gray JE (1842) Descriptions of some new Genera and fifty unrecorded Species of Mammalia. Annals and Magazine of Natural History 10: 255-267. doi: 10.1080/03745484209445232

Hodgson BH (1841) New species of Rhizomys discovered in Nepal. Calcutta Journal of Natural History 2: 60-62.

IUCN (2010) IUCN red list of threatened species. Version 2010.1. Available at www.iucnredlist.org

López-Antońanzas R (2012) Dental morphology and wear pattern in Tachyoryctes (Spalacidae, Rodentia). Mammalia 76: 309-314. doi: 10.1515/mammalia-2012-0018

López-Antońanzas R, Flynn LJ, Knoll F (in press) A comprehensive phylogeny of extinct and extant Rhizomyinae (Rodentia): evidence for multiple intercontinental dispersals. Cladistics.

Misonne X (1971) Order Rodentia. In: Meester J, Setzer HW (Eds) The Mammals of Africa: an identification manual. Smithsonian Institution Press, Washington, 1-39. doi: 10.5479/ si.03629236.298.1

Musser GG, Carleton MD (1993) Family Muridae. In: Wilson DE, Reeder DM (Eds) Mammal Species of the World, Second Edition. The Johns Hopkins University Press, Maryland, 501-755.

Musser GG, Carleton MD (2005) Superfamily Muroidea. In: Wilson DE, Reeder DM (Eds) Mammal Species of the World, Third Edition. The Johns Hopkins University Press, Baltimore, 894-1531.

Rahm U (1980) Die Afrikanische Wurzelratte Tachyoryctes. A. Ziemsen, Lutherstadt Wittenberg.

Thomas O (1915a) Notes on the Asiatic Bamboo-Rats (Rhizomys, etc.). Annals and Magazine of Natural History 16: 56-61.

Thomas O (1915b) Further notes on Asiatic Bamboo-Rats. Annals and Magazine of Natural History 16: 313-317. doi: 10.1080/00222931508693719 